\title{
Hydromorphone (OROS): Its efficacy in acute and chronic pain
}

\author{
Rohit Kumar Verma ${ }^{1 *}$, Piyush Mittal ${ }^{1}$, Ankur Barua ${ }^{2}$ and Suresh Kumar ${ }^{1}$ \\ ${ }^{1}$ Faculty of Pharmacy Practice, School of Pharmacy, International Medical University, 57000 - Malaysia. \\ ${ }^{2}$ Department of Community Medicine, International Medical University, Kuala Lumpur, 57000 - Malaysia.
}

Accepted 16 July, 2013

\begin{abstract}
Pain control in chronic and acute disease conditions such as cancer pain or post-operative pain is often adequate with the help of appropriate pharmacological agent. A comprehensive review of numerous studies conducted to evaluate the efficacy of hydromorphone (OROS) for the management of acute and chronic pain was performed. Data from 17 controlled trials were reviewed, taking into consideration the usefulness of hydromorphone for the management of chronic and acute pain. Heterogeneity of the studies and the small number of patients involved made the conclusion difficult. Overall the studies found that osmotic-controlled released oral delivery system (OROS) hydromorphone that is effective in the management of chronic pain. But comparative studies with other opioid analgesics find little difference in efficacy and side effect profile. OROS hydromorphone is effective in the management of chronic pain, but it's usefulness in acute pain is less conclusive.
\end{abstract}

Key words: Hydromorphone, osmotic-controlled released oral delivery system (OROS), chronic pain, acute pain.

\section{COMMENTARY}

Hydromorphone is a semi-synthetic micro receptor agonist opioid and hydrogenated ketone of morphine (Vallner et al., 1981). It has been used extensively for the management of postoperative pain (Chaplan et al., 1992; Goodarzi, 1999) and is included in clinical practice guidelines for the management of cancer-related pain (Jacox et al., 1993). The oral preparation of hydromorphone is available in different form such as powder, tablets, capsules, modified-release capsules, extended-release (24 h) tablets (Turgeon et al., 2010), controlled-release capsules (Vashi et al., 2005) and immediate-release tablet. Acute pain is immediate and usually of a short duration may be accompanied by anxiety or emotional distress. The cause of acute pain can usually be diagnosed and treated but chronic pain is where the pain last for at least 3 months and the frequency of chronic pain usually happen at most once a week, several times a week or continuously (Pekka et al., 2003).

The use of opioids for neuropathic pain remains controversial but short-term studies provide only equivocal evidence regarding the efficacy of opioids in reducing the intensity of neuropathic pain, whereas intermediate-term studies demonstrate significant efficacy of opioids over placebo, which is likely to be clinically important. Higher dose of opioids is often needed in neuropathic pain as compared to nociceptive pain (Pergolizzi et al., 2008; Eisenberg et al., 2006).

Although there were over 200 publications supporting hydromorphone pain relieving qualities within ten years of its introduction to clinical medicine, hydromorphone is viewed as a second line therapy compared to morphine in both acute and chronic pain (Murray and Neil, 2005). Hydromorphone can be replaced by another opiod 
analgesics if the patient fails to respond well or experience side effects.

Hydromorphone analgesics properties have been studied in various acute pains such as acute trauma pain, oral mucositis pain and burn wound pain. There is also good evidence shown that the analgesic potential of hydromorphone is equivalent to other opiod in acute pain management. On a milligram basis hydromorphone is five times as potent as morphine when given by the oral route, and 8.5 times as potent as morphine when given intravenously (Murray and Neil, 2005; Sarhill et al., 2007).

In a randomized and double-blind clinical trial, 198 adults are presented to the emergency department with acute severe pain and were randomized to receive either intravenous hydromorphone or intravenous morphine. The mean change of pain from baseline to 30 min post baseline in patients receiving hydromorphone was -5.5 numeric rating scales compared to -4.1 in patients received morphine. The adverse reactions are similar in both group of patients and pruritus is excluded in patient with hydromorphone therapy. Hence, intravenous hydromorphone is an alternative towards the intravenous morphine in treating acute, severe pain in the emergency department (Chang et al., 2009).

The short duration of onset of oral hydromorphone limits its use in persistent daily pain. Hence, the extended release form of hydromorphone is used in chronic pain management (Weinstein, 2009). A study on ninety-five adult patients from three Canadian Palliative Care Centers evaluated the safety and efficacy of a new slowrelease preparation of hydromorphone (SRH) with immediate release preparation of hydromorphone $(\mathrm{IRH})$ in the treatment of cancer pain and findings suggest that $\mathrm{SRH}$ is as safe and effective as IRH in the treatment of cancer pain (Bruera et al., 1996).

The osmotic-controlled released oral delivery system (OROS) hydromorphone is a once daily dosage form from which tend to administer the drug at a constant rate and hence, a consistent analgesic effect over $24 \mathrm{~h}$ period is given. However, this dosage form is contraindicated in patients with acute and post-operative pain but is indicated for those in chronic pain (Carter et al., 2010).

In an open-label multicentre trial, patients were stabilised on their previous opioid therapy before being switched to OROS $\AA$ hydromorphone at a ratio of $5: 1$ (morphine sulphate equivalent to hydromorphone hydrochloride) and study concluded that conversion can be achieved without loss of pain control or increase in adverse events, and it also provides additional evidence of safety and efficacy for the proposed 5:1 morphine equivalents:OROS $\AA$ hydromorphone conversion ratio (Wallace et al., 2007).

Study shows that a number of 445 patients where 358 patients are suffering from chronic non-maglinant pain and are treated with novel once daily modified-released hydromorphone. The results show that there is improvement in pain on the extended release hydromorphone in the related patients.

A 39-weeks study on the long-term efficacy and safety of OROS hydromorphone was carried out on 388 patients who received stable doses for non-cancer pain. The analgesic efficacy was maintained throughout the study with only moderate increase in daily dose which suggested limited tolerance effect of the drug. After one year, the therapy with hydromorphone was rated as good, very good and excellent by $72.4 \%$ of patients and $75.9 \%$ of investigators (Coluzzi and Mattia, 2010).

The OROS hydromorphone was well tolerated in clinical trials and the adverse effects shown from mild to moderate are similar with other opioids. Hence, it is an ideal therapy in treating severe pain. Furthermore, in studies of subcutaneous hydromorphone implants, drugs were released steadily for weeks in vitro and in vivo which is suitable for chronic pain management (Weinstein, 2009).

Apart from that, pooled analysis of three open-label studies of OROS hydromorphone in neuropathic and nociceptive nonmaglinant chronic pain was analyzed. The result shows that the therapeutic outcomes for two different pains are similar when hydromorphone is used. However, for some treatment outcome variables, treatment is more effective in treating neuropathic pain. The pooled analysis shows that the use of hydromorphone in neuropathic and nociceptive pain has equivalent therapeutic outcome (Moulin et al., 2010).

In conclusion, it is evident that opioids in non-cancer pain are often related to diseases typical for an elderly population. However, the use of opioids should be individualized and based on tolerability profiles (Eisenberg et al., 2006). It is because pain is a considerable burden to the patients due to co-morbid conditions. Hence, effective pain therapy should be initiated to improve the quality of life and decrease the healthcare use and costs. OROS hydromorphone is suitable in treating chronic pain as it is well tolerated and the plasma concentration is more stable (Lussier et al., 2010). However, most of the evidence that are found from different references stated that hydromorphone are mostly effective in chronic pain management. The supportive evidence of the use of hydromorphone in acute pain management is less likely.

\section{REFERENCES}

Bruera E, Sloan P, Mount B, Scott J, Suarez-Almazor M (1996). A randomized, double-blind, double-dummy, crossover trial comparing the safety and efficacy of oral sustained-release hydromorphone with immediate-release hydromorphone in patients with cancer pain. Canadian Palliative Care Clinical Trials Group. J. Clin. Pharmacol. 14(5):1713-1717.

Carter NJ, Keating GM (2010). OROS $\AA$ hydromorphone prolonged release: A review of its use in the management of chronic, moderate to severe pain. CNS Drugs 24(4):337-61.

Chang AK, Bijur PE, Meyer RH., Kenny MK, Solorzano C, Gallagher EJ (2009). Efficacy and safety profile of a single dose of hydromorphone compared with morphine in older adults with acute, severe pain: A 
prospective, randomized, double-blind clinical trial. Am. J. Geriatr. Pharmacother. 7(1):1-10.

Chaplan SR, Duncan SR, Brodsky JB (1992). Morphine and hydromorphone epidural analgesia. Anesthesiology 77:1090-1094.

Coluzzi F, Mattia C (2010). OROS® Hydromorphopne in chronic pain management: When drug delivery technology matches. Minerva Anestesiologica 76(12):1072-1084.

Eisenberg E, McNicol E, Carr DB (2006). Opioids for neuropathic pain. Cochrane Database Syst. Rev. 19(3):146.

Goodarzi M (1999). Comparison of epidural morphine, hydromorphone and fentanyl for postoperative pain control in children undergoing orthopedic surgery. Pediatr. Anesth. 9:419-422.

Jacox A, Carr D, Payne R (1993). New clinical practice guidelines for the management of pain in patients with cancer. N. Engl. J. Med. 330:651-655.

Lussier D, Richarz U, Finco G (2010). Use of Hydromorphone, with Particular Reference to the OROS® Formulation, in the Elderly. Drugs Aging 27(4):327-335.

Moulin DE, Richarz U, Wallace M, Jacob A, Thipphawong J (2010). Efficacy of the Sustained-Release Hydromorphone in Neuropathic Pain Management: Pooled Analysis of Three Open-Label Studies. J. Pain Palliative Care Pharmacother. 24(3):200-212.

Murray A, Neil AH (2005). Hydromorphone. J. Pain Symptom Manage. 29(5):57-66

Pekka TM, Juha HOT, Riita SA, Esko AK (2003). Chronic Pain and Poor Self-rated Health. JAMA 290(18):2345-2442.

Pergolizzi J, Boger RH, Budd K, Dahan A, Erdine S, Hans G (2008). Opioids and the Management of Chronic Severe Pain in the Elderly: Consensus Statement of an International Expert Panel with Focus on the Six Clinically Most Often Used World Health Organization step III Opioids (Buprenorphine, Fentanyl, Hydromorphone, Methadone, Morphine, Oxycodone). Pain Pract. 8(4):287-313.
Sarhill N, Walsh D, Nelson KA (2007). Hydromorphone: pharmacology and clinical applications in cancer patients. Int. J. Clin. 61(10):16711676.

Turgeon J, Gröning R, Sathyan G, Thipphawong J, Richarz U (2010). The pharmacokinetics of a long-acting OROS hydromorphone formulation. Expert Opin. Drug Deliv. 7(1):137-44.

Vallner JJ, Stewart JT, Kotzan JA, Kirsten EB (1981). Pharmacokinetics and bioavailability of hydromorphone following intravenous and oral administration to human subjects. J. Clin. Pharmacol. 21(4):152-156.

Vashi V, Harris S, El-Tahtawy A, Danlin W, Cipriano A (2005). Clinical Pharmacology and Pharmacokinetics of Once-Daily Hydromorphone Hydrochloride Extended-Release Capsules. J. Clin. Pharmacol. 45(5):547-554

Wallace M, Rauck RL, Moulin D, Thipphawong J, Khanna S, Tudor I C (2007). Once-daily OROS $\AA$ hydromorphone for the management of chronic nonmalignant pain: A dose-conversion and titration study. Int. J. Clin. Pract. 61(10):1671-1676.

Weinstein SM (2009). A new extended release formulation (OROS®) of hydromorphone in management of pain. Therapeut. Clin. Risk Manage. 5:75-80. 